Original Article

\title{
UV-VISIBLE SPECTROSCOPIC AND FTIR ANALYSIS OF SARCOSTEMMA BREVISTIGMA, WIGHT. AND ARN
}

\author{
S. M. DHIVYA*, K. KALAICHELVI \\ PG and Research Department of Botany, Vellalar College for Women (Autonomous), Thindal, Erode, Tamil Nadu, India 638012 \\ Email: diviproject27a8@gmail.com
}

Received: 27 Dec 2016, Revised and Accepted: 20 Mar 2017

\begin{abstract}
Objective: The present study was carried out to characterize the bioactive constituents present in aerial parts of ethanolic extract of Sarcostemma brevistigma using UV-VIS and FTIR.

Methods: FTIR spectroscopy is an established time-saving method to characterize and identify functional groups.

Results: The UV-VIS profile showed different peaks ranging from 200-1044 nm with different absorption respectively. UV-VIS profile showed the peaks at 254.00 and $680.00 \mathrm{~nm}$ for flavonoid. FTIR spectra showed the peak at $3418.85 \mathrm{~cm}-1$ for N-H group. FTIR analysis and UV-VIS analysis showed the presence of flavonoids and a phenolic compound. The FTIR spectra had amply evidenced the occurrence of OH group together with the Terpenoids, and Phenol. The FT-IR spectrum showed the presence of an amine $(\mathrm{N}-\mathrm{H})$, alkyl $(\mathrm{C}-\mathrm{H})$, nitrile $(\mathrm{C} \equiv \mathrm{N})$, halo formyl $(\mathrm{C}=\mathrm{O})$, alkenyl $(\mathrm{C}=\mathrm{C})$, hydroxyl (O-H), haloalkane (C-F), nitrates and carbonate compounds.
\end{abstract}

Conclusion: The results confirm the fact that this plant posse's important bioactive constituent, so further scientific investigation is needed.

Keywords: UV-Vis Spectrum, FTIR, Sarcostemma brevistigma, fingerprint and functional groups

(C) 2017 The Authors. Published by Innovare Academic Sciences Pvt Ltd. This is an open access article under the CC BY license (http://creativecommons.org/licenses/by/4.0/)

DOI: http://dx.doi.org/10.22159/ijcpr.2017v9i3.18890

\section{INTRODUCTION}

Medicinal plant research includes much more than the discovery of new drugs. Natural products, either as pure compounds or as standardized plant extracts, provide unlimited opportunities for the new drug [1]. This field has been expanding and includes diverse subjects as negotiation of power based on medicinal plant knowledge [2]. The different phytoconstituents present in plants include arthra glycosides, bitter drugs, flavonoids, alkaloids, saponins, coumarins, phenol carboxylic acids and terpenes. These phytoconstituents confer specific characteristics and properties to plants. Therefore, the analysis of these constituents would help in determining various biological activities of plants. The spectroscopic technique has become a powerful and analytical tool for the qualitative and quantitative analysis of pharmaceutical and biological materials. Simple, cost-effective and rapid tests for detecting phytocomponents are necessary. Spectroscopic (UV-Vis, FTIR) methods together or separate can be used in this sense as well as conventional methods [3].

The Fourier Transform Infrared spectroscopy (FTIR) allows the analysis of a relevant amount of compositional and structural information in plants. Moreover, FTIR spectroscopy is an established time-saving method to characterize and identified functional groups [4]. Ultraviolet-visible spectrophotometry (UV-Vis) related to the spectroscopy of photons in the UV-visible region. UV-visible spectroscopy uses light in the visible ranges or its adjacent ranges. The colour of the chemicals involved directly affects the absorption in the visible ranges. Molecules undergo electronic transitions in these ranges of the electromagnetic Spectrum [5].

Sarcostemma brevistigma, $W$. and $A$. (Asclepiadaceae) is an evergreen, laticiferous, woody creeper found throughout India. It is commonly known as Somakalli and Kodikalli. Sarcostemma brevistigma is an important plant species traditionally used in Indian system of medicine mainly for the treatment of various diseases such as asthma, rheumatisum, arthritis, joints pain, ear ache, dog bite, chronic ulcer, fever, cough, cold, menstural disorder, bone fracture, bronchitis, dysentery, dyspepsia, leprosy, tumor, constipation, skin diseases, ascites and stomach distention [6]. The main objective of the present study is to identify the phytoconstituents of Sarcostemma brevistigma whole plant extract by UV-VIS spectrum and FTIR profile.

\section{MATERIALS AND METHODS}

Collection of plant materials

The plant Sarcostemma brevistigma was collected from Pillur Beat (Pillur slope RF and Nellithurai RF), Karamadai Range, Western Ghats, Tamil Nadu, India. The authenticity of the plant was confirmed in Botanical Survey of India, Southern Circle, Coimbatore by referring the deposited specimen. The whole plant was washed under running tap water, shade dried at room temperature and powdered.

Preparation of plant extract for UV-VIS spectrum and FTIR analysis

The shade dried whole plant of Sarcostemma brevistigma (at $25^{\circ} \mathrm{C}$ ) was powdered in a mechanical grinder. 20 gms of whole plant powder was weighed; $150 \mathrm{ml}$ of solvent was added and kept for $3 \mathrm{~d}$. The extract was filtered using Whattman No.1 filter paper and the supernatant was collected. The residue was again extracted two times (with $3 \mathrm{~d}$ of the interval for each extraction) and supernatants were collected. The supernatants were pooled and evaporated (at room temperature, $28 \pm 1{ }^{\circ} \mathrm{C}$ ) until the volume was reduced to 150 ml. Extract of the whole plant powder with ethanol was prepared and stored in airtight bottles for subsequent analysis.

\section{UV-VIS spectrum analysis}

The extract was centrifuged at 3000rpm for $10 \mathrm{~min}$ and filtered through Whatmann No.1 filter paper. The sample was diluted to $1: 10$ with the same solvent. The extract was scanned at wavelength ranging from 200 to $1100 \mathrm{~nm}$ using Perkin Elmer Spectrophotometer and the characteristic peaks were detected. The peak values of the UV-VIS were recorded.

\section{FTIR analysis}

Dried powder (ethanolic extract) of test plant was used for FTIR analysis. $1 \mathrm{mg}$ of the dried powder was encapsulated in $10 \mathrm{mg}$ of $\mathrm{KBr}$ pellet, in 
order to prepare translucent sample discs. The powdered sample of the pellet was loaded in FTIR spectroscope (Shimadzu, Japan), with a Scan range from 400 to $4000 \mathrm{~cm}^{-1}$ with a resolution of $4 \mathrm{~cm}^{-1}$.

\section{RESULTS}

The qualitative UV-VIS spectrum profile of ethanol extract of Sarcostemma brevistigma was selected at a wavelength from 200 to $1100 \mathrm{~nm}$ due to the sharpness of the peaks and proper baseline. The profile showed the peaks at 254, 680 and $1044 \mathrm{~nm}$ with the absorption of $0.524,0.110$, and 0.154 respectively (table 1 , fig. 1 ).

The FTIR spectrum was used to identify the functional groups of the active components present in extract based on the peaks values in the region of IR radiation. When the extract was passed into the FTIR, the functional groups of the components were separated based on its peaks ratio. The results of FTIR peak values and functional groups were represented in table 2 . The FTIR spectrum profile was illustrated in fig. 2. The FTIR gave broad peak at $3418.85 \mathrm{~cm}^{-1}$ which indicated the presence of $\mathrm{N}-\mathrm{H}$ stretching. It gave a strong peak at 2856.12 and $2922.66 \mathrm{~cm}^{-1}$ which indicated the presence of $\mathrm{C}-\mathrm{H}$ stretching, $1244.58 \mathrm{~cm}^{-1}$ attributed to $0-\mathrm{H}$ bending vibrations, the peak around $1319.8 \mathrm{~cm}^{-1}$ are due to alkyl group, $1621.67 \mathrm{~cm}^{-1}$ alkenyl $\mathrm{C}=\mathrm{C}$ stretching, $1731.61 \mathrm{~cm}^{-1}$ streching vibration halo formyl group, peak obtained at $2346.42 \mathrm{~cm}^{-1}$ indicated the presence of $\mathrm{C} \equiv \mathrm{N}$ stretching, and the peaks at 1376.7 and $1423.96 \mathrm{~cm}^{-1}$ indicated the presence of nitrates and carbonates. There was no absorbance in between the region $2220-2260 \mathrm{~cm}^{-1}$ indicates that there was no cyanide group in this extract. This results shows that Sarcostemma brevistigma does not contain any toxic substances. The FTIR spectrum confirmed the presence of alcohols, phenols, alkanes, alkynes, alkyl halides, aldehydes, aromatics, nitro compounds and amines in powder pellet.

Table 1: UV-VIS Spectrum Peak values of ethanolic extract of Sarcostemma brevistigma

\begin{tabular}{|c|c|c|}
\hline S. No. & Wavelength nm. & Abs. \\
\hline 1 & 1044.00 & 0.154 \\
\hline 2 & 1021.00 & 0.148 \\
\hline 3 & 950.00 & 0.137 \\
\hline 4 & 895.00 & 0.125 \\
\hline 5 & 877.00 & 0.147 \\
\hline 6 & 853.00 & 0.127 \\
\hline 7 & 814.00 & 0.111 \\
\hline 8 & 797.00 & 0.114 \\
\hline 9 & 763.00 & 0.111 \\
\hline 10 & 680.00 & 0.110 \\
\hline 11 & 271.00 & 0.588 \\
\hline 12 & 1071.00 & 0.143 \\
\hline 13 & 1027.00 & 0.146 \\
\hline 14 & 975.00 & 0.129 \\
\hline 15 & 967.00 & 0.129 \\
\hline 16 & 904.00 & 0.118 \\
\hline 17 & 886.00 & 0.122 \\
\hline 18 & 863.00 & 0.121 \\
\hline 19 & 254.00 & 0.524 \\
\hline
\end{tabular}

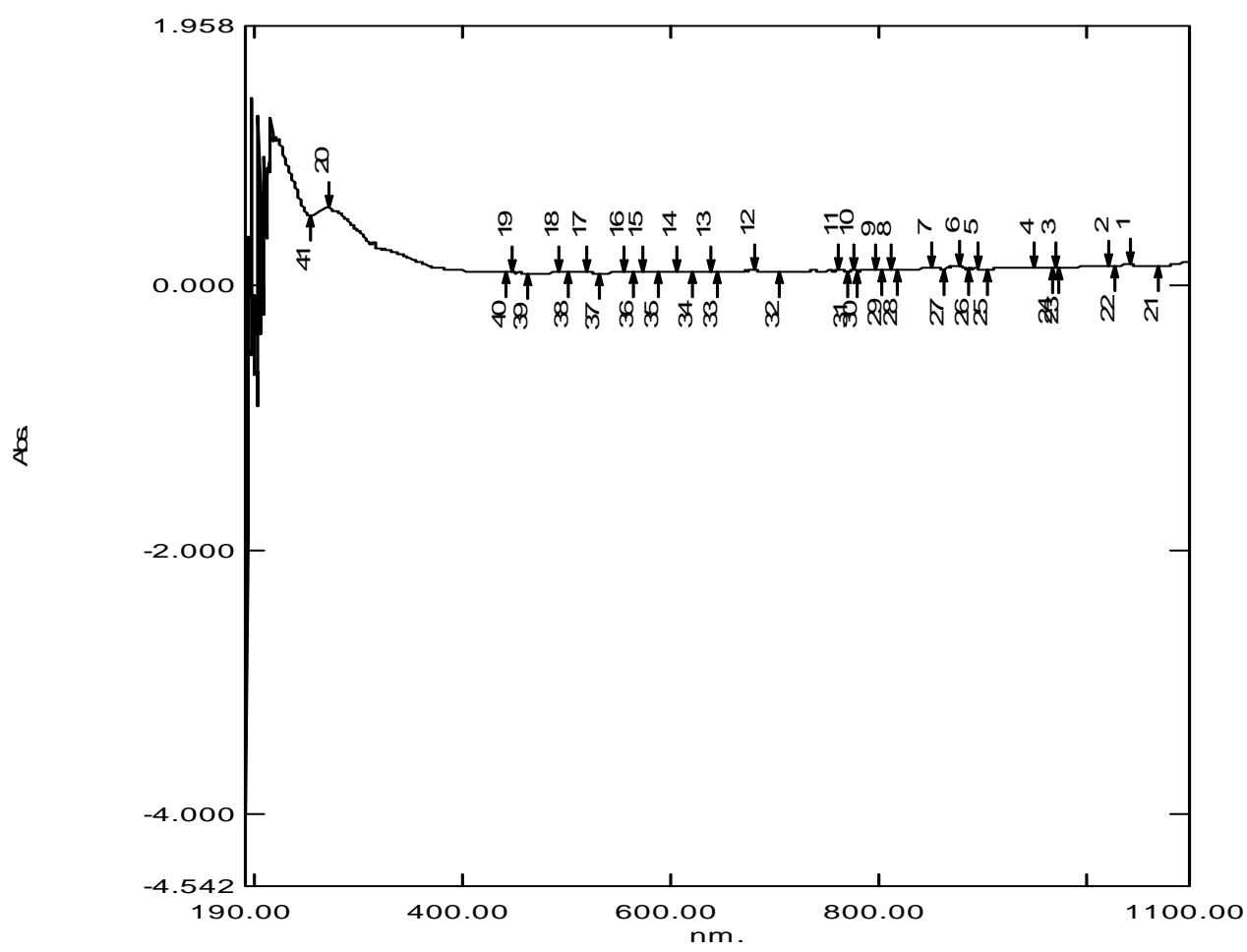

Fig. 1: UV-VIS Spectrum of ethanolic extract of Sarcostemma brevistigma 
Table 2: FTIR Peak values and functional groups of pellet of Sarcostemma brevistigma

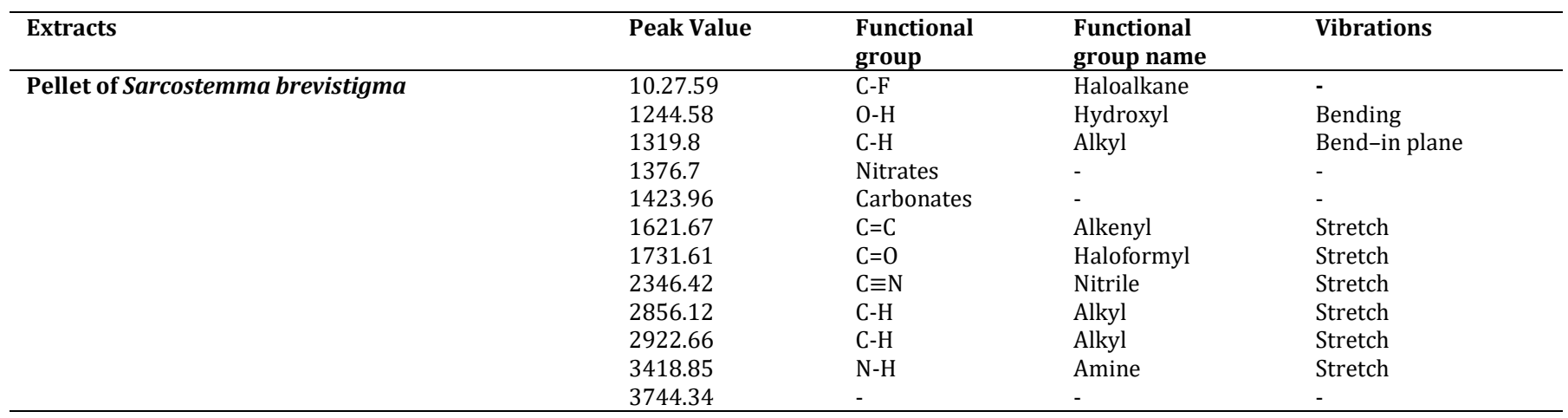

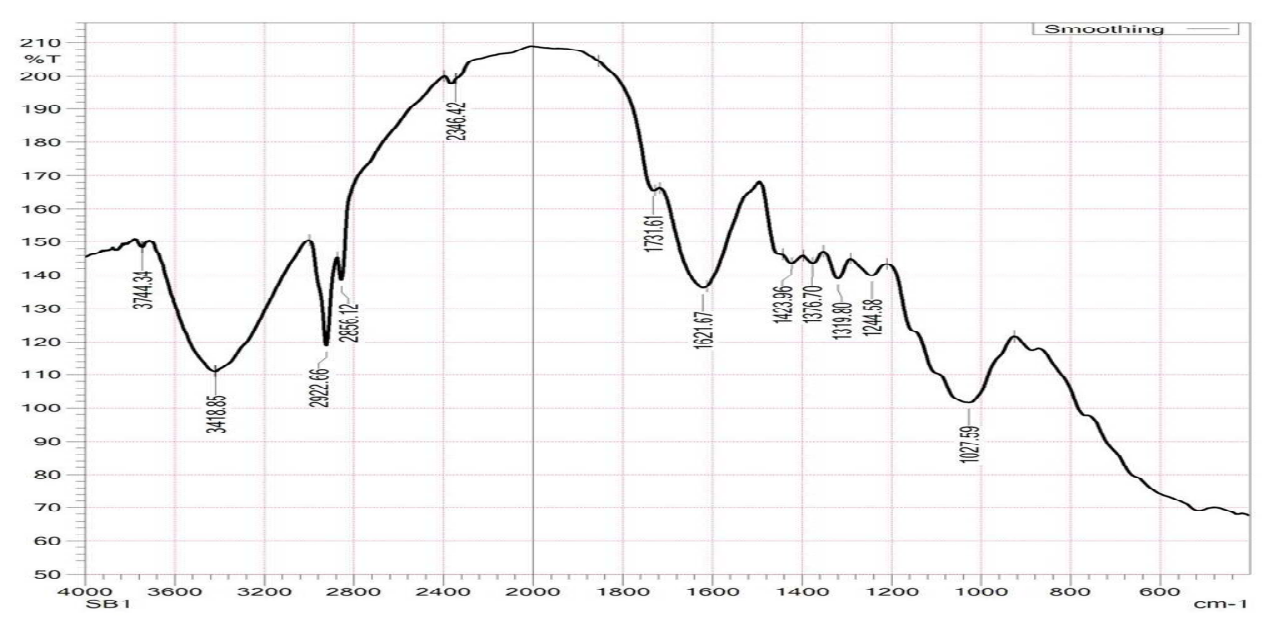

Fig. 2: FT-IR Spectrum of pellet of Sarcostemma brevistigma

\section{DISCUSSION}

Characterization of secondary metabolite fingerprint by chromatography and spectroscopy provide valuable information about the qualitative and quantitative formulation of plant species and their pattern of recognition by chemometric. The UV-VIS spectroscopy offers a simple, technique to identify the main phytochemicals, discriminating between the lipophilic and hydrophilic molecules in relation to the polarity. Spectroscopic (UVVIS, FTIR) methods together or separate can be used in this sense as well as conventional methods [7].

Fourier Transform Infrared Spectroscopy (FTIR) is a high-resolution analytical technique to identify the chemical constituents and elucidate the structural compounds [8]. FTIR offers a rapid and non-destructive investigation to fingerprint plant extracts or powders [9].

Therefore in the present study FTIR techniques were employed to evaluate the IR finger print of Sarcostemma brevistigma. The results (table 2) revealed the presence of alkaloids due to $\mathrm{N}-\mathrm{H}$ stretching, polyphenols and flavonoids due to $\mathrm{O}-\mathrm{H}$ stretching, terpens due to $\mathrm{C}$ $\mathrm{H}$ group [10]. The FTIR spectrum confirmed the presence of alcohols, phenols, alkanes, alkynes, alkyl halides, aldehydes, carboxylic acids and amines in the test plant.

All these compounds belong to secondary plant metabolites as per researcher explanations [11]. The presence of glycosides and alkaloids in Sarcostemma brevistigma may be associated with their use by traditional medicine practitioners in healthcare systems in the treatment of cough, fever and cold [12]. These were confirmed by FTIR spectrophotometer study that predicted the presence of the groups: $\mathrm{C}-\mathrm{F}, \mathrm{O}-\mathrm{H}, \mathrm{C}-\mathrm{H}, \mathrm{C}=\mathrm{C}, \mathrm{C}=\mathrm{O}, \mathrm{C} \equiv \mathrm{N}, \mathrm{N}-\mathrm{H}, \mathrm{C}-\mathrm{H}$, carbonates and nitrates stretching. The presence of characteristic functional groups of carboxylic acids, anhydrides, alcohols, phenols, amines, amides, esters, ethers, sulphur derivatives, glycosides, nitrates, nitriles, organic halogens and carbohydrate could be responsible for the various medicinal properties of Sarcostemma brevistigma [13]. Based on the functional group analysis, Sarcostemma brevistigma doesn't contain any toxic compounds.

\section{CONCLUSION}

In the present study UV-VIS spectrum and FTIR analysis of whole plant of Sarcostemma brevistigma showed the presence of phenolic compounds and flavonoids which are responsible for various medicinal properties of test plant. Further, this compound can be isolated further screened for different kind of biological activities depending their therapeutic uses. Further research will be needed to find out the structural analysis of flavonoid compound by use of different analytical methods such as NMR and Mass spectrophotometer.

\section{ACKNOWLEDGEMENT}

We, the authors are thankful to Central Laboratory in Vellalar College for Women for providing facilities and encouragement.

\section{CONFLICT OF INTERESTS}

We declare that we have no conflict of interest

\section{REFERENCES}

1. Parekh J, Chanda V. In vitro antimicrobial activity and phytochemical analysis of some Indian medicinal plants. Turkish J Biol 2007;31:53-8.

2. Garro LC. Intercultural variation folk medicinal knowledge: a comparison between curers and noncurers. American Anthropologist 1986;88:351-70.

3. Aysal P, Ambrus AD, Lehotay SJ, Cannavan A. Validation of an efficient method for the determination of pesticide residues in 
fruits and vegetables using ethyl acetate for extraction. J Environ Sci Heal 2007;42:481-90.

4. Grube M, Muter O, Strikauska S, Gavare M, Limane B. Application of FT-IR spectroscopy for control of the medium composition during the biodegradation of nitro aromatic compounds. J Indian Microbiol Biotechnol 2008;35:1545-9.

5. Gunasekaran S. UV-VIS spectroscopic analysis of blood serum. Asian J Microbiol Biotech Environ Sci 2003;5:581-2.

6. Dahiya K, Verma M, Dhankhar R., Singh V, Ghalaut PS, Seth S. Alteration of ischemia modified albumin and nitric oxide levels in hypothyroidism. Clin Lab 2014;60:969-72.

7. Ibrahim M, Hameed AJ, Jalbout A. Molecular spectroscopic study of river nile sediment in the greater cairo region. Appl Spectroscopy 2008;62:306-11.

8. Komal Kumar J, Devi Prasad AG. Identification and comparison of biomolecules in medicinal plants of Tephrosia tinctoria and Atylosia albicans by using FTIR. Romanian J Biophys 2011;21:63-71.

9. Hashimoto A, Kameoka T. Applications of infrared spectroscopy to biochemical, food, and agricultural processes. Appl Spectrosc Rev 2008;43:416-51.
10. Sahu N, Saxena J. Phytochemical analysis of Bougainvillea glabra, Choisy. By FTIR and UV-VIS Spectroscopic analysis. Int J Pharm Sci Rev Res 2013;21:196-8.

11. Skoog A, Holler EJ, Crouch SR. Principles of instrumental analysis. 6 Edition; 2007. p. 1039.

12. Starlin T, Arul Raj C, Ragavendran P, Gopalakrishnan VK. Phytochemical screening, functional groups and element analysis of Tylophora pauciflora Wight and Arn. Int Res J Pharm 2012;3:180-3.

13. Maobe MAG, Nyarango RM. Fourier transformer infra-red spectrophotometer analysis of Warburgia ugandensis medicinal herb used for the treatment of Diabetes, Malaria and Pneumonia in Kisii Region, Southwest Kenya. Global J Pharmacol 2013;7:61-8.

\section{How to cite this article}

- $\quad$ SM Dhivya, K Kalaichelvi. UV-Vis spectroscopic and FTIR analysis of Sarcostemma brevistigma, wight. and arn. Int J Curr Pharm Res 2017;9(3):44-49. 